Teles, R.M.S.; Nogueira, S.M.B. Influência de programas mundiais na sustentabilidade do turismo em áreas protegidas da região metropolitana da Baixada Santista (SP). Revista Brasileira de Ecoturismo, São Paulo, v.9, n.1, fev/abr2016, pp.152-173.

\title{
Influência de programas mundiais na sustentabilidade do turismo em áreas protegidas da região metropolitana da Baixada Santista (SP) ${ }^{1}$
}

\begin{abstract}
Influence of global programs on the sustainability of tourism in protected areas of the metropolitan area of Baixada Santista (SP, Brazil)
\end{abstract}

\author{
Reinaldo Miranda Sá Teles, Silvia Maria Bellato Nogueira
}

\begin{abstract}
RESUMO
A presente análise objetivou avaliar as ações de planejamento e gestão do Turismo em áreas naturais protegidas da Região Metropolitana da Baixada Santista (RMBS) no Estado de São Paulo (Brasil), identificando em que nível estas ações foram influenciadas por conceitos e métodos propostos em dois programas mundiais da Organização das Nações Unidas (ONU): os Objetivos do Desenvolvimento do Milênio (ODM) e a Convenção sobre Diversidade Biológica (CDB). Enquanto a CDB já é amplamente difundida em programas de manejo e gestão do Turismo em áreas protegidas no Brasil, os ODM tiveram pouca penetração nesta temática. Subdivididos em oito metas globais, quatro delas têm amplo potencial para contribuir na elaboração de novas metodologias na gestão do Turismo em áreas naturais protegidas: o ODM 01 (redução da fome e da miséria); o ODM 03 (promoção da igualdade de gênero); o ODM 07 (respeito ao meio ambiente) e 0 ODM 08 (estabelecimento de parcerias para o desenvolvimento sustentável). Como resultado, a pesquisa demonstrou haver influência apenas indireta das metodologias propostas pelos ODM no que tange ao planejamento e gestão de atividades turísticas sustentáveis nas áreas naturais protegidas da RMBS, enquanto a influência da CDB foi facilmente identificável nas políticas e ações de planejamento e gestão do Turismo. Foram alcançadas algumas conclusões, como por exemplo, a de que os ODM passaram por uma clara adaptação ao contexto brasileiro por meio de políticas públicas, preferencialmente com relação ao ODM 01 (redução da pobreza). Quanto ao ODM 07, no qual o Turismo Sustentável insere-se como atividade econômica a ser incentivada na elevação do nível de renda das populações locais e em prol da conservação ambiental, este carece fortemente de políticas públicas assertivas. Sendo colocado pela ONU como primordial para o sucesso dos ODM em países em desenvolvimento, o Turismo Sustentável com base nos ODM e na CDB pode proporcionar significativos ganhos a áreas como a RMBS, permeada por complexas configurações urbanas, ambientais e sociais.
\end{abstract}

PALAVRAS-CHAVE: Objetivos do Milênio; Diversidade Biológica; Turismo Sustentável; Áreas Protegidas; Comunidades Locais. 


\section{ABSTRACT}

This analysis aims to evaluate the action planning and management of tourism in protected natural areas of the Santos Metropolitan Region (RMBS) in the State of São Paulo (Brazil), whilst identifying at what level these actions were influenced by concepts and methods proposed in two global programs of the United Nations (UN): the Millennium Development Goals (MDGs) and the Convention on Biological Diversity (CBD). While the CBD is already widespread in management programs and management of tourism in protected areas in Brazil, the MDGs have had little penetration on this theme. Subdivided into eight global goals, four of them have vast potential to contribute to the development of new methodologies in the management of tourism in protected natural areas: the ODM 01 (reducing hunger and poverty); MDG 03 (promoting gender equality); MDG 07 (respect for the environment) and the MDGs 08 (establishment of partnerships for sustainable development). As a result, the survey showed that there was only indirect influence of methodologies proposed by the MDGs with regards to planning and management of sustainable tourism activities in protected natural areas of RMBS. While the influence of the CBD was easily identifiable in policy and action planning and tourism management, some conclusions were reached, including the MDGs passing by a clear adaptation to the Brazilian context through public policies, preferably in relation to the MDGs 01 (poverty reduction). As for the MDGs 07 , in which Sustainable Tourism is inserted as an economic activity to be encouraged in raising the income level of local populations while conserving the environment, this strongly lacks assertive public policy. It has been placed by the UN as paramount to the success of the MDGs in developing countries Sustainable Tourism based on the MDGs and the CBD can provide significant gains in areas such as RMBS, permeated by complex urban, environmental and social settings.

KEYWORDS: Millennium Goals; Biological Diversity; Sustainable Tourism; Protected Areas; Local Communities.

\section{Contextualização do objeto de estudo}

\section{O Território e a Sociedade}

Criada no âmbito das Constituições Federal de 1988 e Estadual de 1989, época de forte expansão das atividades industriais no Estado de São Paulo, a RMBS (Figura 1) é formada por nove municípios que abrangem 2.422,77 km², todos com uma complexa restrição do uso da terra devido aos inúmeros e crescentes impactos socioambientais ali registrados, muitos deles, diretamente ocasionados pela expansão urbana e por atividades de segmentos do turismo que não consideraram em sua formação os atuais preceitos de sustentabilidade.

Estima-se em apenas 2\% a proporção do território total do Estado de São Paulo protegido sob a forma de Unidades de Conservação. Isto torna ainda mais importante a proporção de áreas naturais protegidas na RMBS, uma vez que a distribuição delas neste território corresponde a aproximadamente $42 \%$ de sua área total. Esta configuração territorial e socioambiental favorece o segmento de Turismo de Natureza, devido à qualidade paisagística e ambiental de seus ambientes naturais relativamente conservados, além do forte apelo exercido pelas inúmeras praias da região.

Com relação à complexidade urbana e socioambiental é atualmente a terceira maior região metropolitana do Estado de São Paulo em termos populacionais, com 1,7 milhões de habitantes (SÃO PAULO, 2010), total este que pode ultrapassar três e meio milhões de turistas em períodos de férias, atraídos pelas suas 83 praias (SÃO PAULO, 2006). 


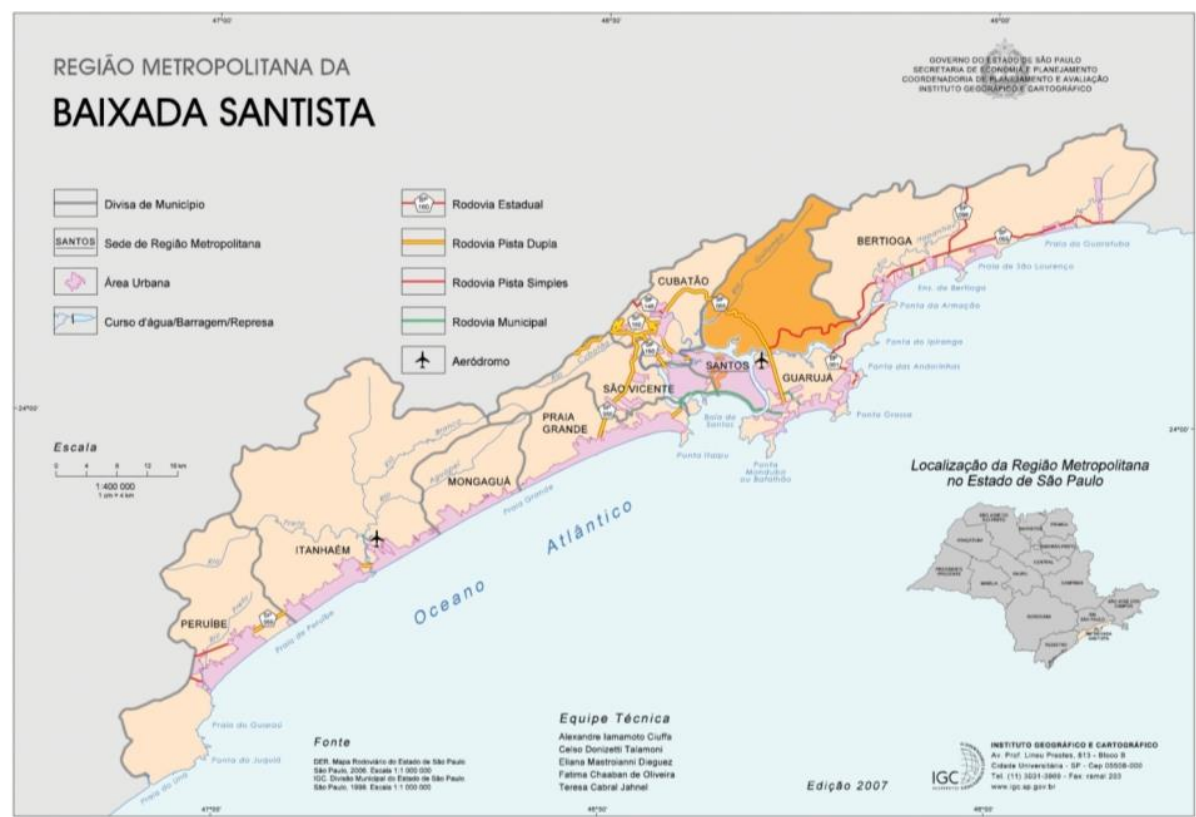

Figura 1: Região Metropolitana da Baixada Santista.

Figure 1: Metropolitan region of Baixada Santista (SP, Brazil)

Fonte: Instituto Geográfico e Cartográfico (2007).

Source: Instituto Geográfico e Cartográfico (2007).

Estima-se em apenas 2\% a proporção do território total do Estado de São Paulo protegido sob a forma de Unidades de Conservação. Isto torna ainda mais importante a proporção de áreas naturais protegidas na RMBS, uma vez que a distribuição delas neste território corresponde a aproximadamente $42 \%$ de sua área total. Esta configuração territorial e socioambiental favorece o segmento de Turismo de Natureza, devido à qualidade paisagística e ambiental de seus ambientes naturais relativamente conservados, além do forte apelo exercido pelas inúmeras praias da região.

Com relação à complexidade urbana e socioambiental é atualmente a terceira maior região metropolitana do Estado de São Paulo em termos populacionais, com 1,7 milhões de habitantes (SÃO PAULO, 2010), total este que pode ultrapassar três e meio milhões de turistas em períodos de férias, atraídos pelas suas 83 praias (SÃO PAULO, 2006).

O PIB da RMBS - R $\$ 40$ bilhões - correspondente a 5\% do PIB do Estado de São Paulo (IBGE, 2010). As atividades econômicas de maior destaque são a indústria petroquímica (Cubatão é o maior polo petroquímico do país e responsável por cerca de $60 \%$ da produção do Estado de São Paulo); e as atividades portuárias (Santos movimenta cerca de 100 milhões de toneladas de mercadorias e fatura cerca de U\$ 120 bilhões ao ano); e o setor terciário (correspondendo a 70\% do PIB e 73,42\% dos empregos formais da RMBS) (SÃO PAULO, 2010a).

A RMBS receberá, nos próximos anos, uma série de investimentos por conta do início da exploração da camada do Pré-Sal na Bacia Sedimentar de Santos (SP) e da duplicação da capacidade de seu porto (o maior da América Latina). São empreendimentos grandiosos que levantam profundas preocupações quanto aos impactos ambientais negativos que podem causar nos ecossistemas de suas áreas naturais remanescentes, pois, se por um lado o desenvolvimento econômico traz benefícios à população por conta de novos e melhores empregos e melhores 
infraestruturas, por outro, vem a inevitável expansão urbana e com ela todas as demandas de estruturas e serviços, além da geração de mais resíduos e efluentes.

A RMBS teve um crescimento populacional de 0,92\% entre 2013 e 2014, ocupando $015^{\circ}$ lugar no quadro geral das regiões metropolitanas brasileiras, lembrando que os municípios de 'médio porte' no Brasil tiveram a maior taxa de crescimento populacional. Esses municípios, em geral, são importantes centros regionais em seus estados, ou integram as principais regiões metropolitanas do país, configurando-se como áreas de atividade migratória (BAIXADA SANTISTA..., 2014).

Zündt (2006) acrescenta que o boom populacional atual rumo à RMBS se caracteriza pela forte expansão das atividades turística, petrolífera e portuária. $\mathrm{O}$ autor acrescenta que a área urbana da RMBS possui alto grau de conurbação e devido à configuração geomorfológica no formato estreito e confinado entre o litoral e a Serra do Mar, com amplos espaços cobertos por vegetação protegida por Lei, é uma região com uma complexa situação ambiental, social e econômica. São Paulo (2010a) acrescenta ainda, que vem aumentando a população em áreas periféricas, intensificando-se o fenômeno da conurbação, só interrompido por restrições de ordem física.

Como lembra FIERZ (2008), a região costeira do Estado de São Paulo, como um todo, tem sofrido grande transformação negativa da paisagem e, por conseguinte, isto afeta o Turismo de Natureza de modo negativo, pois este depende das paisagens conservadas para o seu desenvolvimento pleno.

O Zoneamento Ecológico-Econômico RMBS tende a combater estes fatores, porém, é recente: foi regulamentado pelo Decreto Estadual 58.996/2013, pretendendo promover o ordenamento territorial e disciplinar os usos dos recursos naturais da RMBS.

\section{O Turismo e as Áreas Naturais Protegidas}

No Brasil, o conceito de áreas naturais protegidas se configurou no termo "Unidades de Conservação" (áreas cujo propósito é a proteção da biodiversidade, dos ecossistemas e da paisagem, legisladas a partir do Sistema Nacional de Unidades de Conservação - SNUC -, criado pela Lei 9.985 de 18/07/2000), e os Territórios de Ocupação Tradicional (Terras Indígenas e Territórios Remanescentes de Quilombos). Esses são os dois principais grupos de áreas naturais protegidas incluídos no Plano Estratégico Nacional de Áreas naturais protegidas (PNAP) por intermédio do Decreto o 5.758 de 13/04/2006, visando estabelecer um sistema abrangente e representativo de áreas terrestres e marinhas a serem protegidas pelo poder público, que seja ecologicamente representativo e efetivamente manejado (INESC, 2011).

A maioria das áreas protegidas no Brasil foi criada por decreto. Quanto aos Planos de Manejo e de Uso Público a realidade é bastante heterogênea, sendo que muitas não possuem estes documentos, outras os possuem, mas em situação de defasagem diante das demandas. Poucas ainda conseguem administrar de modo sustentável e equilibrado as atividades de Turismo dentro e no entorno delas. $\mathrm{O}$ desenvolvimento do Turismo em áreas protegidas no Brasil, portanto, reflete esta realidade. 
O país então ficou estagnado nesta situação do Turismo com relação às áreas naturais protegidas, que, conforme Neiman e Mendonça (2002) estão voltadas para a execução das atividades com um caráter empresarial, priorizando aspectos voltados à prestação de serviços e ao retorno econômico em detrimento das prioridades conservacionistas e da participação comunitária.

Para os autores este contexto inflexível põe em risco os valores locais, sendo necessária a criação de uma rede de pessoas, organizadas no sentido de experimentar situações inovadoras no uso turístico de áreas naturais protegidas, sendo na sua visão uma ação urgente, na medida em que se vê crescer, com grande velocidade, o consumo das paisagens e recursos destas áreas e uma padronização chocante dos lugares onde a personalidade da cultura local é forte e expressiva (o que vai ao encontro do ODM08).

INESC (2011) salienta que o caminho que os governos têm trilhado com relação às suas áreas naturais protegidas é a chamada "solução de mercado", a ser alcançada por meio de diferentes receitas. Os autores lembram que, em decorrência da natureza polissêmica do conceito de desenvolvimento sustentável, sua implementação prática aparece atrelada ao suposto melhor "desempenho técnico" e dentro das regras do jogo do sistema de mercado capitalista, sem atingir nem questionar as regras e relações de poder, de propriedade e de apropriação capitalistas, causas estruturais da degradação ambiental, da pobreza, da diferenciação social e da injustiça.

Por enquanto, conforme Backes et al. (2002), o Turismo convencional tem vencido esta disputa, apostando mais na lógica do crescimento econômico do que na sustentabilidade e, quando o faz, é para garantir minimamente a sua sobrevivência como negócio, abdicando de voltar-se para a dimensão social do tema e para os afetados negativamente pelo mercado ecoturístico. As autoras ressaltam que normas não podem sozinhas substituir uma política turística ampla e integral, necessária para a mudança de tendências.

Quanto ao Estado de São Paulo, as áreas naturais protegidas denominamse Unidades de Conservação e são criadas com base legal na Constituição Federal (Cap. V. art. 225, inciso $1^{\circ}$ item III) e Estadual (Cap. IV, art. 193, item III) ambas de 1989. São administradas pela Secretaria do Meio Ambiente do Estado de São Paulo. (SÃO PAULO, 2010b).

Estima-se em $2 \%$ a proporção do território total do Estado de São Paulo protegido sob a forma de Unidades de Conservação integrais (916.582 hectares) e sustentáveis (4.607.491 hectares). Apenas $25 \%$ da cobertura vegetal natural remanescente estão sob o domínio do Estado, estando o restante sob o domínio de propriedades privadas e áreas federais (SÃO PAULO, 2011).

Dentre os principais problemas históricos referentes ao modelo de implantação destas áreas protegidas, alguns persistem em diferentes intensidades como: a irregular manutenção de populações em seu interior (questão fundiária); a incorporação de áreas ambientalmente degradadas; a não ocupação por meio de infraestrutura ou de atividades; as políticas setoriais conflitantes; a pouca interação ou poucos benefícios para as populações locais; entre outros.

Conforme Vallejo (s/d), a deficiência das políticas públicas brasileiras para o Turismo em áreas naturais protegidas é o grande responsável pelo lento progresso neste setor. Ele observa que as decisões tomadas pelos governos, num primeiro 
momento, indicam manifestação de importância em relação ao tema do Turismo, mas, posteriormente, ocorre a ausência de decisões suplementares necessárias ao seu efetivo funcionamento.

Nos países onde o gerenciamento de áreas naturais protegidas é mais avançado, o Turismo fornece os meios financeiros para a conservação e justifica a criação de novas áreas. No Brasil, especificamente no Estado de São Paulo, o Turismo em áreas naturais protegidas é permitido dependendo de sua categoria de manejo (áreas mais ou menos restritivas).

Duas Leis e um Decreto destacam-se com relação ao Uso Público (Turismo) em Áreas Naturais Protegidas no estado de São Paulo. O SIEFLOR (Sistema Estadual de Florestas por meio do Decreto 51.453/2006) que aborda o tema Turismo ainda de modo superficial e sua futura substituta (em elaboração) denominada SIGAP-SP (Sistema de Informação e Gestão de Áreas Protegidas e de Interesse Ambiental do Estado de São Paulo), que aborda de modo mais assertivo as atividades de visitação pública nas áreas protegidas paulistas.

O SIGAP-SP será inovador no sentido em que visará integrar ações do poder público e consolidar o Sistema Nacional de Unidades de Conservação no Estado de São Paulo, destacando-se parágrafos e artigos que incentivam a promoção da educação e interpretação ambiental, da recreação em contato com a natureza e do turismo ecológico e que promovem a busca pelo apoio e a cooperação de organizações não governamentais, de organizações privadas e pessoas físicas, para o desenvolvimento de atividades de lazer e uso público nestas áreas.

O Decreto 57.401/2011, por sua vez, foi inovador no sentido de legalizar e incentivar programas de parcerias entre setores privados e públicos para sua melhor gestão (desde que se encontrem sob a administração do Estado), destacando-se, na implantação das atividades de lazer e Turismo em áreas protegidas, objetivos como a participação de populações locais e de organização privadas; a sustentabilidade econômica e a autonomia administrativa e financeira destas áreas; a promoção da educação, interpretação e recreação ambiental; entre outros objetivos.

Entretanto Irving (2000), quanto ao uso turístico destas áreas, acrescenta importantes fatores que dificultam a implantação de um modelo sustentável, persistente ao longo dos anos: a questão fundiária, onde $85 \%$ das Unidades de Conservação no sudeste do Brasil possuem populações em seu interior; a deficiência na capacitação de pessoal para projetos ecoturísticos; a precariedade de indicadores de qualidade ambiental e social para o setor; os conflitos com as comunidades locais dentro e no entorno das áreas naturais protegidas; a carência de dados técnicos sobre as áreas naturais protegidas; entre outros.

Takahashi (2004) acrescenta que a complexidade de garantir o sucesso do manejo de áreas naturais protegidas, exige, entre outras iniciativas, a avaliação contínua de resultados e a geração de renda (o que atualmente começa a ser feito por meio das terceirizações), para garantir a sustentabilidade tanto da área protegida, quanto da atividade turística (lembrando que em 2002, com a regulamentação do SNUC pelo decreto №. 4.340, a exploração de bens e serviços em unidades de conservação foi instituída e reconhecida no Brasil).

Quanto à RMBS, o segmento de Turismo de Natureza é forte devido à qualidade paisagística de seus ambientes naturais, além do forte apelo exercido 
pelas inúmeras praias da região. Entretanto, como reforça Zündt (2006) há na RMBS uma complexa restrição do estoque de terras para regular o preço imobiliário, acrescentando a isto, problemas do sistema viário saturado; conflitos pelo uso da água que começa a se tornar escassa e cada vez mais poluída; fortes impactos sobre as áreas de mananciais, florestas e mangue; entre outros problemas de caráter mais setorizados.

Por isso, suas áreas naturais protegidas também são penalizadas, uma vez que as ocupações irregulares nas áreas periféricas decorrentes do boom populacional tendem a comprometer gravemente suas áreas de amortecimento, geralmente recobertas por remanescentes florestais da Mata Atlântica, agravando a desorganização urbana, fruto da pouca eficiência das políticas de planejamento territorial na região (SÃO PAULO, 1997).

Todos os fatores elencados tornam ainda mais importantes o território ocupado por áreas naturais protegidas na RMBS, visto que a distribuição destas áreas em seus nove municípios é expressiva (Tabela 1).

Tabela 1: Região Metropolitana da Baixada Santista: Áreas naturais protegidas Federais e Estaduais em Relação à Área Total por Município na Baixada Santista (1).

Table 1: Metropolitan region of Baixada Santista: Natural Protected Areas Federal and State in Relation to Total Area by Municipality in Baixada Santista.

\begin{tabular}{|c|c|c|c|c|}
\hline Município & $\begin{array}{c}\text { Área Total } \\
\text { (ha) }\end{array}$ & $\begin{array}{c}\text { Vegetação } \\
\text { Natural (ha) }\end{array}$ & $\begin{array}{c}\text { Área Preservada } \\
\text { (ha) }\end{array}$ & $\begin{array}{c}\text { Relação } \\
\text { AP/AT (\%) }\end{array}$ \\
\hline Bertioga & 48.200 & 39.466 & $34.734,53$ & 88,01 \\
\hline Cubatão & 14.800 & 8.509 & $6.188,24$ & 72,73 \\
\hline Guarujá & 13.700 & 6.484 & --- & --- \\
\hline Itanhaém & 58.100 & 49.320 & $23.889,70$ & 48,44 \\
\hline Mongaguá & 13.500 & 10.910 & $6.987,03$ & 64,04 \\
\hline Peruíbe & 32.800 & 23.716 & $17.962,89$ & 75,74 \\
\hline Praia Grande & 14.500 & 9.588 & $5.188,09$ & 54,11 \\
\hline Santos & 27.100 & 18.389 & $11.461,48$ & 62,33 \\
\hline
\end{tabular}

Fonte: Instituto Florestal - Inventário Florestal da Vegetação Natural do Estado de São Paulo (SÃO PAULO - ESTADO, 2013).

Source: Instituto Florestal - Inventário Florestal da Vegetação Natural do Estado de São Paulo (SÃO PAULO - ESTADO, 2013).

(1) Foram contabilizadas as áreas de Unidades de Conservação (Parques Estaduais e Estações Ecológicas), Reservas Particulares do Patrimônio Natural e Terras Indígenas.

Sendo que, as áreas naturais protegidas presentes na RMBS distribuem-se em diversas categorias de manejo, o que acarreta em amplas e diferentes restrições legais de uso destas áreas. Em sua maioria, assim como em todo o país, foram criadas por decreto e a situação de seus planos de manejo e gestão é variada, sendo que algumas ainda não os concluíram.

Destaque é dado ao Parque Estadual da Serra do Mar, que na RMBS ocupa uma área de 88.641 ha, representando para alguns de seus municípios, quase 50 
\% de área ocupada por áreas protegidas. Os municípios da RMBS também fazem parte da Reserva da Biosfera da Mata Atlântica e da Reserva da Biosfera do Cinturão Verde de São Paulo, criadas pela UNESCO em 1991 e 1994, áreas reconhecidas em nível mundial como fundamentais para a conservação da biodiversidade da Mata Atlântica e dos seus remanescentes (CORRÊA, 1995).

Algumas particularidades destacam-se: $70 \%$ dos remanescentes do bioma Mata Atlântica no Estado de São Paulo pertencem a proprietários privados, entretanto, poucos converteram suas áreas em Reservas Particulares do Patrimônio Natural, sendo a área ocupada por esta categoria de proteção na RMBS é ainda menor, representando $1.574,00$ hectares. As Terras Indígenas são administradas pelo governo federal (Fundação Nacional do Índio), mas fazem parte do mosaico de áreas protegidas da RMBS, passíveis de receberem projetos de uso turístico sustentável em suas áreas.

\section{Marco teórico e conceitual}

O marco teórico desta pesquisa se apoia na temática da sustentabilidade do Turismo sob a ótica de programas mundiais de desenvolvimento socioeconômico e gestão de territórios. Apoia-se neste sentido, no corpo teórico-conceitual e por vezes legal de dois dos mais importantes programas mundiais que tanto restringem como condicionam e influenciam o uso turístico de áreas protegidas e suas áreas de entorno, conforme anteriormente citado: os Objetivos do Desenvolvimento do Milênio e a Convenção sobre Diversidade Biológica.

\section{Os Objetivos do Desenvolvimento do Milênio}

Ao longo do século XX e intensificando-se no atual, a ONU passou a promover os ideais do desenvolvimento sustentável com ênfase no usufruto dos recursos ambientais de modo conservacionista e democrático entre os povos, o que se reforçou a partir de 2000, com a elaboração da denominada Agenda do Milênio, redigida em Nova York, onde os ODM foram definidos e ratificados por mais de 130 nações signatárias (UNB et al., 2004).

O conjunto de metodologias sugeridas pelos ODM tem como fundamento principal o estímulo, por meio de metas, da efetivação de políticas públicas executadas em cooperação com setores privados das sociedades de cada país signatário, visando à melhoria das condições de vida de sua população, num processo que tem 15 anos e que culminará, em 2015, no programa denominado Objetivos do Desenvolvimento Sustentável (ODS), também conhecido como Pós2015.

A respeito de propostas de desenvolvimento sustentável a partir de metas, como é o caso dos ODM, Veiga (2010) observa ser importante o papel de indicadores que mensuram o progresso do desenvolvimento, mesmo que continuem a existir clivagens, tanto conceituais quanto operacionais para o sucesso destas avaliações. Na sua visão os ODM pecam por problemas como: não deixam totalmente explícitos os critérios de análise de seu progresso; possuem dependência excessiva de indicadores econômicos; insuficiente especificidade cultural das nações; insuficiente apoio do setor público e privado; fragilidade para lidar com as "grandes questões" que o mundo enfrenta; etc. 
Porém, segundo a ONU, entraves persistem, como a diminuição da ajuda financeira de países ricos aos pobres; declínio dos recursos naturais com perdas contínuas de espécies animais e vegetais; e fortes impactos das mudanças climáticas, sendo o progresso em direção aos ODM desigual não só entre regiões e países, mas entre grupos populacionais internos, com os mais pobres e os que vivem em áreas rurais de cada país (ONU, 2013).

Entretanto, os ODM colocaram efetivamente o bem-estar humano e a redução da pobreza e da fome no centro das discussões para a efetivação do Desenvolvimento Sustentável e, com base em uma agenda de compromissos (Agenda do Milênio), foram estruturados em oito etapas subdivididas em 18 metas e 48 indicadores, mensuráveis e temporalmente delimitadas, a serem alcançadas pelos estados-membros até 2015, devendo ser avaliadas periodicamente nas escalas nacional, regional e global.

\section{O Desenvolvimento Sustentável e o Turismo Sustentável na ótica das Nações Unidas}

O Turismo, segundo as metas da ONU contribui para o desenvolvimento socioeconômico dos países por meio de divisas; estimula o desenvolvimento da infraestrutura de transporte; estimula o comércio interno e externo fortalecendo as cadeias de fornecimento; promove a integração de economias; reduz a carga sobre os orçamentos públicos através de iniciativas público-privadas; gera trabalho decente e produtivo para os jovens; oferece oportunidades para a cooperação bilateral, multilateral e sub-regional entre os países; e aprimora o uso das tecnologias integrando empresas de turismo em mercados turísticos globais.

O recorte central das propostas elaboradas pela ONU, que norteiam os fundamentos teóricos e conceituais desta pesquisa refere-se à temática do Turismo Sustentável, no sentido de atividade econômica passível de contribuir com a superação da pobreza e a promoção da conservação ambiental, vislumbrando, porém, a gestão do Turismo por meio de algumas das metas dos Objetivos do Desenvolvimento do Milênio.

A mobilização dos países signatários em prol do Desenvolvimento Sustentável remonta 1972, quando da Conferência sobre o Ambiente Humano, onde foram divulgados os princípios que visavam à necessidade de inspirar os povos do mundo em prol da conservação ambiental e da melhoria das condições de vida do ser humano (ONU. 2013).

Depois novos programas foram elaborados: o Relatório Brundtland (1987), quando foi sistematizado o conceito de Desenvolvimento Sustentável: "aquele que atende as necessidades atuais do ser humano, com equilíbrio ambiental e sem comprometer a habilidade das futuras gerações de atender as suas próprias necessidades" (BRUNDTLAND, 1991); a Conferência da ONU sobre o Meio Ambiente e Desenvolvimento ou ECO-92 (onde foi formatada a Agenda 21); a Convenção sobre Diversidade Biológica (1992); a Declaração do Milênio (2000) que atribuiu ao Programa das Nações Unidas para o Desenvolvimento a responsabilidade de coordenar as partes no alcance do Desenvolvimento Sustentável); os Objetivos de Desenvolvimento do Milênio também em 2000 (ratificados por 199 países); a Estratégia de Maurício em 2005; e a Rio+20 em 2012. 
Como o paradigma da sustentabilidade supõe uma reorientação do Turismo, a ONU propôs reconhecer apenas o Turismo que se desenvolve com respeito ao meio ambiente em seus aspectos natural cultural e social, ou seja, aquele que permitindo ao turista uma abordagem participativa da experiência, desfrutando de um intercâmbio positivo com os residentes de uma comunidade e seus valores, sendo os benefícios da atividade compartilhados igualmente (UNWTO, 2011).

O Turismo Sustentável ganhou um corpo conceitual sólido em 1999, com o Código Mundial de Ética do Turismo, que pregava a minimização dos efeitos negativos do Turismo no meio ambiente e no patrimônio cultural, aumentando a busca pelos benefícios para os destinos turísticos devendo ser privilegiadas políticas de Turismo Sustentável, além de propor a redução da pressão sobre 0 meio ambiente e a aumentar o impacto benéfico na economia local (REGULES et al., 2007).

Também os princípios de Lanzarote (1995) para o incentivo ao Turismo Sustentável, à sua época, convergiam claramente com as Metas do Milênio desenvolvidas pela ONU, com relação ao Turismo Sustentável (convergindo com os ODM 01, 03, 07 e 08, quando afirma que a conservação, proteção e valorização do património natural e cultural só surge num espaço privilegiado de cooperação o que implica num desafio de inovação cultural, tecnológica e profissional, realizando um grande esforço para criar e desenvolver ferramentas de planejamento e gestão integrada.

Em 2003, na China, foi criado pela Organização Mundial do Turismo (OMT), o Comitê Mundial de Ética do Turismo juntamente com os Programas "Sustainable Development of Tourism (SDT)" e "Sustainable Tourism Eliminating Poverty (STEP)", tendo sido adaptados no Brasil com o programa "Força Tarefa Internacional para o Desenvolvimento do Turismo Sustentável (FTI-DTS)". São atualmente as mais importantes referências para o desenvolvimento sustentável do Turismo no mundo. São seis etapas propostas (UNEP/UNWTO, 2005):

1. Emprego e capacitação das populações menos favorecidas no Turismo;

2. Venda direta de bens e serviços para os visitantes pelas populações locais ou para empresas de Turismo;

3. Criação e gestão de pequenas empresas, empresas comunitárias ou joint ventures para os pobres (economia formal);

4. Distribuição mais igualitária dos lucros da cadeia de Turismo;

5. Incentivo ao voluntariado no apoio ao trabalhador local, ao Turismo e aos turistas;

6.Investimento em infraestrutura estimulada pelo Turismo;

Os princípios do Turismo Sustentável foram definitivamente consolidados com a Estratégia de Maurício (2005) e passaram a ser importantes contribuintes para o crescimento econômico das nações. Foi então que a OMT foi incumbida pela ONU da difusão do Turismo Sustentável no mundo, em consonância com os ODM, estando o Turismo conceitualmente e organizacionalmente vinculado a vários dos 
ODM, porém mais particularmente aos ODM01 (redução da pobreza); ODM03 (igualdade de gênero); ODM07 (desenvolvimento sustentável); e ODM08 (cooperação local e regional).

A ONU interpreta o Turismo como atividade multiplicadora e estratégica na transição para uma economia verde. Para tanto, elaboraram o critério Delivering as One no domínio do Turismo, visando acelerar o progresso em direção aos ODM, financiadas por meio de políticas e investimentos públicos e privados pelas nações signatárias e, como observado, incentivando a pesquisa científica para o Turismo, gerando diretrizes, ferramentas, capacitação e referências técnicas mais efetivas, tais como (UNWTO, 2013):

- Utilização e manutenção adequada dos serviços ambientais;

- Respeito à autenticidade sociocultural das comunidades de acolhimento;

- Viabilidade de longo prazo das operações econômicas em Turismo Sustentável, distribuídas de forma justa, incluindo a geração de renda para as comunidades de acolhimento;

- Participação informada dos interessados, bem como liderança política para a construção de consenso;

- Introdução de medidas preventivas / corretivas para minimização dos impactos;

- Aumento da experiência significativa para os turistas promovendo práticas de Turismo sustentável entre eles.

Neste sentido, em 2007 foi aprovada a Declaração de Davos, onde a OMT apostou no setor privado para maximizar os impactos positivos do Turismo Sustentável, objetivando posicioná-lo na vanguarda dos esforços globais para combater as alterações climáticas, por meio da criação de empregos verdes e infraestrutura.

Também em 2007, para dar suporte aos programas de uso sustentável da biodiversidade, a CDB incorporou uma metodologia de precificação ou valoração da biodiversidade elaborada em um estudo denominado "A Economia dos Ecossistemas e da Biodiversidade" ou TEEB (The economics of ecosystems and biodiversirty), vinculada ao Programa da ONU para o Meio Ambiente, que propõe uma solução às dificuldades de valoração ambiental, por ser capaz de dar um valor econômico expresso em dinheiro a qualquer função ecossistêmica ou a quaisquer valores culturais associados à biodiversidade, permitindo uma simplificação dos valores da biodiversidade necessária para ser apropriada pelo mercado (TERRA DE DIREITOS, 2012).

Em 2010 o Programa da ONU para o Meio Ambiente (PNUMA) lançou a Força Tarefa Internacional sobre o Desenvolvimento Sustentável do Turismo, buscando identificar e divulgar iniciativas bem-sucedidas. Essas medidas resultaram, em 2012, na inclusão, pela primeira vez, do Turismo como mecanismo de desenvolvimento econômico em um documento final de uma Conferência da ONU (Rio+20) e também nos resultados da 11aㅡ Reunião da Convenção sobre Diversidade Biológica (Índia), onde políticas e planos de ação foram elaborados 
para efetivar o Turismo como gerador de renda para comunidades locais e como tendo um papel a desempenhar em um futuro mais justo e sustentável (ONU, 2012).

Atualmente a OMT e a ONU passaram a oferecer uma estrutura de parcerias cada vez mais especializadas para o aprimoramento do Turismo Sustentável, seja no setor público, privado ou da sociedade civil, por meio de programas complementares, tais como:

- CSR in Tourism (Corporate Social Responsibility), onde as organizações assumem a responsabilidade em busca de um setor de Turismo mais sustentável e competitivo;

- UN Global Compact e TourPact, incentivando empresas a abraçarem princípios universais em prol de negócios inovadores, gerando benefícios sociais e econômicos para as comunidades de acolhimento, utilizando ferramentas que visem o aumento da competitividade e sustentabilidade por meio de parcerias;

- Supply Chain Sustainability, fornecendo recursos, ferramentas e exemplos de boas práticas pela ONU para ajudar no desenvolvimento de cadeias de abastecimento do Turismo sustentáveis;

- UN Business Partnership Gateway, portal de negócios da ONU para facilitação de parcerias com o setor privado.

O governo brasileiro, por usa vez, tem abordado a questão do Turismo como meio de inclusão social à luz dos ODM e da OMT, estimulando por meio de projetos o seu potencial como vetor para a redução da pobreza (ODM 01) e proteção ao meio ambiente (ODM 07), porém ainda muito centrado no nível federal. (IPEA, 2005).

Neste sentido Dowbor (1994) observa que no Brasil, o Turismo, para caminhar efetivamente para a gestão sustentável dos recursos destinados ao desenvolvimento, depende da descentralização no nível Federal, caminhando para uma gestão feita pelos próprios municípios, o que dinamizaria a economia de baixo para cima, com projetos específicos para cada realidade e utilizando melhor os poucos recursos disponíveis.

\section{Sobre Diversidade Biológica (CDB)}

Estabelecida também durante a ECO-92 e tendo sido reconhecida por mais de 190 países é um dos mais importantes instrumentos internacionais relacionados ao meio ambiente, visto que abarca tudo o que se refere direta ou indiretamente à biodiversidade, funcionando como um arcabouço legal e político para diversas outras convenções e acordos ambientais específicos, tendo estabelecido programas de trabalho temáticos e levando a diversas iniciativas transversais (BRASIL, 2000).

Segundo a Organização não Governamental Terra de Direitos (2012), na CDB três necessidades fundamentais aparecem com relação ao Turismo em áreas protegidas: a capacitação e a promoção de concessões de Turismo; a promoção do Turismo em comunidades indígenas; e a promoção de mecanismos de compensação de carbono para o setor do Turismo. 
Neste estudo é observado que, enquanto a perda da biodiversidade e dos serviços dos ecossistemas é uma preocupação global, é ao nível local dos países em desenvolvimento que elas têm maior impacto, pois, a maior parte da biodiversidade mundial está concentrada nestes lugares, e neste sentido, a biodiversidade pode ser uma das suas vantagens turísticas mais competitivas para receber uma parcela crescente do mercado de Turismo internacional.

No Brasil, foi ratificada pelo Decreto 02/1994, sendo promulgada pelo Decreto 2.519/1998. Referindo-se à biodiversidade em três níveis: ecossistemas, espécies e recursos genéticos, estrutura-se em três bases (conservação da diversidade biológica; uso sustentável da biodiversidade; e repartição justa e equitativa dos benefícios provenientes da utilização dos recursos genéticos).

A ONU, por meio da Organização Mundial do Turismo, elegeu a Convenção sobre Diversidade Biológica como parâmetro para o alcance da conservação ambiental no mundo, acrescentando que este processo deve se dar de modo a beneficiar democraticamente as populações mais vulneráveis (uso mais igualitário dos Serviços Ecossistêmicos).

Assim como os ODM, também pode ser considerada como um desdobramento da Agenda 21, estabelecendo obrigações e procedimentos para os envolvidos (os órgãos oficiais que atuam na gestão da biodiversidade de cada nação). No Brasil foi criado o PRONABIO - Programa Nacional de Diversidade Biológica - com o objetivo de promover a implantação dos compromissos assumidos pelo Brasil junto à CDB estimulando parcerias com a sociedade civil na conservação e utilização sustentável da diversidade biológica e estimulando a cooperação entre suas autoridades governamentais e setor privado na elaboração de métodos de utilização sustentável de recursos biológicos (BRASIL, 2000).

Também é objetivo geral da CDB a utilização sustentável da biodiversidade e a repartição justa e equitativa dos benefícios derivados da utilização dos recursos genéticos. Neste sentido, no âmbito de acordos específicos surgiu o programa "Diretrizes para o Turismo Sustentável e a Biodiversidade", destacando-se importantes determinações que têm consequências diretas no planejamento de atividades turísticas em áreas naturais protegidas: a estreita dependência dos recursos biológicos para comunidades locais e indígenas; repartir equitativamente os benefícios derivados da utilização do conhecimento tradicional, de inovações e de práticas relevantes à conservação da diversidade biológica e à utilização sustentável de seus componentes; o papel fundamental da mulher na conservação e na utilização sustentável da diversidade biológica; a necessidade de promover a cooperação internacional, regional e local entre governos e organizações empresariais e da sociedade civil para a conservação da diversidade biológica e a utilização sustentável de seus componentes (BRASIL, 2000).

A CDB tem sido gradativamente convocada pela ONU a se alinhar conceitualmente, metodologicamente e por meio de ações conjuntas e sincronizadas, aos objetivos propostos pelos ODM, visto que ambos os programas nasceram pela iniciativa da ONU. Deste modo, a CDB passou a incorporar oficialmente que a conservação ambiental, além dos objetivos de preservação da biodiversidade, deve ter como um dos seus fins a disponibilização dos Serviços Ambientais para o bem-estar dos povos, podendo contribuir significativamente para o desenvolvimento sustentável e mais particularmente, para a melhoria das 
condições socioeconômicas das populações menos favorecidas envolvidas com esta temática.

Embora a CDB tenha sido a principal referência na elaboração das metas do eixo ambiental dos ODM (ODM07), nem sempre esta vinculação foi percebida. A ONU tem constatado esta distinção entre os ODM e a CDB em muitos países signatários. Enquanto os ODM estão mais voltados para ações de redução da pobreza, a CDB, por meio dos protocolos de Kyoto de 1997 e Nagoya de 2010 (LINO, 2011), estabeleceram metas e políticas de conservação ambiental, sobretudo em países tropicais. Deste modo os discursos permanecem separados, quando ambas são oriundas das Nações Unidas e com objetivos muito próximos, sendo na verdade, complementares. A ONU declarou recentemente que esta falha será profundamente corrigida na elaboração das metas para o "Pós-2015" (ODS), quando as questões ambientais e o Turismo serão tratados como temas de primeira linha no alcance do Desenvolvimento Sustentável pelas nações em desenvolvimento.

\section{Procedimentos metodológicos adotados}

Os ODM destacados nesta pesquisa e as respectivas metas a eles associadas, foram avaliados quanto a sua incorporação conceitual, metodológica e/ou programática nas atividades de Turismo Sustentável nas áreas protegidas da RMBS e no seu entorno.

Para atender a especificidade desta investigação, as formas de pesquisa adotadas foram às consultas em sites especializados sobre o assunto, além da revisão bibliográfica sobre os temas analisados. Neste sentido, a pesquisa foi feita com base em fontes de informação indiretas (pesquisa documental, bibliográfica e digital), visando sua fundamentação teórica para justificar os limites e contribuições dos temas envolvidos: socioeconomia da região analisada; áreas naturais protegidas; Turismo Sustentável sob a ótica da ONU; grau de conhecimento dos ODM e da CDB nas Áreas Protegidas da RMBS e sua relação com o Turismo, entre outros temas secundários.

Também ocorreu a fase descritiva, visando somente observar, registrar, analisar e correlacionar fatos e/ou fenômenos, procurando descobrir, com a precisão possível, a frequência com que ocorrem, sua relação e sua conexão com outras variáveis, sua natureza e suas características, seja na vida social, política ou econômica da região.

Estão previstas fases posteriores de análises complementares em campo e a previsão de término da pesquisa é 2015, ano em que finda o prazo da implantação dos ODM no mundo e se inicia um programa mais específico, denominado Objetivos do Desenvolvimento Sustentável (ODS), uma vez que a pesquisa se insere num projeto mais abrangente, que visa selecionar algumas das áreas protegidas analisadas, para a proposição de ações pautadas nos ODM e que possam contribuir para o aprofundamento das práticas de Turismo Sustentável nestas áreas, assim como na redução da pobreza para as comunidades locais envolvidas neste processo, a partir da distribuição mais justa dos lucros resultantes das cadeias de Turismo envolvidas.

Os quatro ODM elencados nesta pesquisa, como claramente propícios a receberem contribuições do desenvolvimento de um modelo de Turismo 
Sustentável em áreas naturais protegidas, encontram-se descritos como segue (quadro 01), retirados de UNCTAD (2007) e BRASIL (2013), ressaltando-se que, as avaliações do progresso dos ODMs no Brasil foram obtidas com base em indicadores armazenados na Base de Dados Globais dos ODMs junto a ONU (UNDP/DESA, 2014).

Quadro 1: Indicadores para Monitorar o Progresso dos Objetivos do Desenvolvimento do Milênio e sua Adaptação ao Turismo no Brasil (UNCTAD, 2007; BRASIL, 2013; e UNDP/DESA, 2014).

Table 1: Indicators to Monitor the progress of the Millennium Development Goals and its adaptation to Tourism in Brazil (UNCTAD, 2007; BRAZIL , 2013; and UNDP / DESA , 2014).

ODM 01: Erradicar a Extrema Pobreza e a Fome. Metas Universais.

- 1.A: Reduzir pela metade entre 1990 e 2015 a \% de pessoas com rendimento inferior a 1 dólar por dia.

- 1.B: Alcançar o emprego pleno e produtivo e do trabalho digno para todos, incluindo mulheres e jovens.

- 1.C: Reduzir pela metade, entre 1990 e 2015, a proporção de pessoas que sofrem de fome.

\section{ODM03: Igualdade entre Sexos e Empoderamento das Mulheres. Metas Universais.}

-3.A. Eliminar a disparidade de gênero em todos os níveis de ensino, se possível.

-3.B Diminuir a percentagem de mulheres assalariadas no setor não agrícola e elevá-la em demais setores.

3.C Aumentar a proporção de mulheres exercendo mandatos no parlamento nacional.

\section{ODM 07: Garantir a Sustentabilidade Ambiental. Metas Universais.}

- 7.A: Integrar os princípios do desenvolvimento sustentável nas políticas e programas nacionais.

- 7.B: Alcançar redução significativa na taxa de perda da biodiversidade.

- $\quad$ 7.C: Reduzir pela metade a proporção de pessoas sem acesso à água potável e ao saneamento básico.

- 7.D:Ter alcançado melhora significativa nas vidas de pelo menos 100 milhões de moradores de favelas.

\section{- ODM 08: Parcerias para o Desenvolvimento Sustentável. Metas Universais.}

- 8A: Desenvolver um sistema aberto, previsível e não discriminatório baseado em regras e finanças para a boa governança em prol da redução da pobreza.

- 8B: Atender às necessidades de acesso a tarifas e quotas comerciais mais justas.

- 8C: Não se aplica (especial para países sem litoral).

- 8D: Tratar globalmente o problema da dívida dos países em desenvolvimento, mediante medidas que tornem a dívida sustentável em longo prazo.

- 8E: Proporcionar o acesso a medicamentos essenciais a preços acessíveis nos países em desenvolvimento.

- 8F: Tornar acessíveis aos mais pobres os benefícios das novas tecnologias. 


\section{Resultados obtidos}

Os resultados dos levantamentos referentes aos projetos de Turismo identificados para as áreas protegidas da RMBS e seu entorno apontam para poucos programas que se referem diretamente aos ODM em suas descrições conceituais e metodológicas. Deste modo, os dados foram categorizados de acordo com a sua vinculação a algum tipo de iniciativa oriunda direta ou indireta dos ODM e a CDB, e secundariamente, a outros programas mundiais voltados ao Desenvolvimento Sustentável e ao Turismo sustentável.

Deste modo, quanto ao ODM01 (redução da pobreza), não foram identificados projetos e ações com referências conceituais e metodológicas diretas aos ODM, desenvolvidos especificamente para a RMBS. Já para o contexto brasileiro foram identificados dados que demonstram como o desenvolvimento do Turismo tem contribuído para o seu desenvolvimento econômico:

- A participação do Turismo na economia brasileira continua forte e grande geradora de empregos com a consequente redução da pobreza. Representando 3,7\% do PIB com US\$ 76,1 bilhões de faturamento anual entre 2003 a 2009 o setor cresceu 32,4\% enquanto a economia brasileira apresentou expansão de $24,6 \%$, representando um crescimento anual de 6,64\%\%. (IBGE, 2010).

- A participação de segmentos especializados no Turismo de Natureza (Ecoturismo, Turismo de Aventura, etc.) ainda é pouco explorada no país, embora o potencial seja grande: $62 \%$ da área territorial do Brasil correspondam à vegetação nativa e o litoral tenha quase $7.500 \mathrm{~km}$ de extensão. Com o propósito de incentivar esse segmento, o Ministério do Turismo e o Ministério do Meio Ambiente planejam ampliar a visitação aos parques nacionais para ter, até 2016, cadeias completas de negócios turísticos nos Parques Nacionais do Brasil. (BRASIL / MINTUR, 2013).

Quanto ao mercado de trabalho de Turismo para mulheres brasileiras (contribuindo para o alcance do ODM03) também não foram identificados projetos e ações específicas para a RMBS, sendo que os dados apresentados demonstram como o desenvolvimento do Turismo tem contribuído para a igualdade entre sexos e a igualdade de gênero no mercado do Turismo no Brasil. (IPEA, 2011).

- O Turismo emprega alta proporção de mulheres. No entanto, é grave o problema da segregação de gênero por categoria profissional ou diferenças salariais de acordo com o gênero.

- As ocupações por gênero em 2010 indicavam uma concentração das mulheres atuando no Turismo em funções especificas e de hierarquia inferior, como por exemplo: cozinheiras (62\%); copeiras (72\%); camareiras (92\%); emissoras de passagens (65\%); etc.

Quanto ao ODM07 (sustentabilidade ambiental relacionado ao Turismo), muitas ações e projetos foram identificados, tanto com referência direta aos ODM e à CDB, como os não diretamente pautados nesta temática. As políticas e ações mais relevantes identificadas foram (ONU, 2013 e IPEA, 2014): 
- Programa de Parcerias para as Unidades de Conservação do ESP (Decreto 57.401 de 06/10/2011). Inspirado pelas metas da CDB foi instituído visando à sustentabilidade de suas Unidades de Conservação por mecanismos de concessão de serviços de Ecoturismo à iniciativa privada, ONGs, comunidades locais e consórcios nos editais de licitação.

- Em 2013 uma agenda de compromissos ambientais para os ODM na RMBS foi proposta: implantação de uma agenda integrada entre os nove municípios; construção de um modelo de desenvolvimento sustentável em função das novas demandas sociais, ambientais e urbanas acumuladas; identificação dos desafios impostos em função da ampliação de portos, construção de rodovias e exploração do pré-sal; e observância da efetiva mitigação dos efeitos negativos decorrentes dos novos empreendimentos econômicos em curso. (INSITUTO PÓLIS, 2013).

- Reservas da Biosfera (da Mata Atlântica e do Cinturão Verde da Cidade de São Paulo). Com metas pautadas pela UNESCO (1991 e 1994) atuam no território da RMBS desenvolvendo ações que contemplam o desenvolvimento sustentável e o estímulo à conservação ambiental por meio de diversas ações, que no Turismo estimulam à conservação ambiental por meio da elaboração de normas de certificação do Turismo sustentável, ajuste de diretrizes do Turismo no contexto da CDB, entre outros.

Quanto à influência das parcerias globais, regionais e locais para o desenvolvimento sustentável e sua influência no Turismo (ODM08) para a RMBS, com referências diretas aos ODM e CDB, foram identificadas nos programas desenvolvidos pelas Reservas da Biosfera (da Mata Atlântica e do Cinturão Verde da Cidade de São Paulo), por meio do intercâmbio de experiências, gestão participativa, criação de associações comunitárias e pelo estímulo às parcerias com prefeituras, ONGs, setor privado, voluntariado e governos em todas as esferas do poder.

Neste sentido, como destacam Teles e Nogueira (2013), foram muito aprofundadas como método as técnicas de análise da Avaliação Ecossistêmica do Milênio (solicitada aos países signatários dos ODM pela ONU no ano 2000 visando orientar objetivos de pesquisas científicas em áreas protegidas mundialmente, incluindo áreas de Reservas da Biosfera) e bastante relevantes e inovadoras no panorama de pesquisas e proposições de políticas publicas que unem figuras conflitantes em um mesmo espaço (áreas complexamente urbanizadas contíguas à áreas florestais legalmente protegidas), que possam implantar um sistema de gestão participativo e estratégias de conservação de ambientes naturais em torno das maiores metrópoles do mundo.

Os autores destacam, que para a ONU, a figura das Reservas da Biosfera constitui atualmente o que há de mais moderno, no sentido da gestão de áreas florestais contíguas a complexos urbanos, sendo a AEM uma coletânea de métodos e técnicas que objetivam a integração dos resultados de levantamentos referentes aos ecossistemas, na forma de uma avaliação multiescala, onde a investigação do objeto proposto (investigação local), não se desconecta do seu contexto regional e mundial (referente ao fenômeno da metropolização no Brasil e no mundo). 


\section{Conclusões}

É fato que no Brasil, as políticas e as consequentes ações programáticas oriundas da adaptação dos ODM e da CDB que delas deveriam resultar, penetraram de modo heterogêneo e difuso no efetivo planejamento ambiental e na gestão e uso turístico das áreas protegidas, sendo muito mais nitidamente identificáveis os conceitos e métodos da CDB em tais programas do que os oriundos dos ODM.

Quanto ao ODM07, a integração dos princípios do desenvolvimento sustentável nas políticas e programas de Turismo em áreas protegidas é difícil de avaliar, pois a meta é qualitativa, havendo avanços na criação de áreas protegidas, mas lento progresso no seu uso turístico comprovadamente sustentável.

Quanto ao ODM08, às ações relacionadas à governança também não possuem indicadores precisos, entretanto, a colaboração entre setores público e privado, associações independentes e participantes da sociedade civil têm avançado (mesmo que lentamente), no sentido de organizar e capacitar as comunidades de acolhimento, através de parcerias de apoio ao desenvolvimento do Turismo e do crescimento econômico local.

Embora os ODM sejam criticados por se basearem em medidas qualitativas difíceis de serem mensuradas ou quantitativas que nivelam a realidade, estes têm sido considerados fundamentais como parâmetro para a adoção de políticas e programas sustentáveis gradativamente testados e aprimorados no mundo todo.

É importante ressaltar que o lento crescimento da participação das comunidades locais no entorno das áreas protegidas no Brasil, de um modo geral, tanto no processo decisório das metas a serem alcançadas com o Turismo, e, sobretudo, no crescimento e distribuição dos negócios, renda e frutos ligados à sua cadeia produtiva nestas localidades, prejudicando o pleno exercício dos métodos propostos pelos ODM e pela CDB no tocante ao seu uso turístico sustentável.

Futuramente nesta pesquisa, os ODM 01, 03, 07 e 08 orientarão e definição medidas mitigadoras a serem organizadas em cartilhas educacionais e difundidas entre os atores envolvidos no uso turístico sustentável das áreas protegidas da RMBS e seu entorno, incentivando o contato com os ODM e seus benefícios para o aprimoramento do Turismo Sustentável nestas áreas, indo ao alcance de uma rede de políticas, ações e programas de incentivo ao desenvolvimento sustentável.

\section{Referências bibliográficas}

BAIXADA SANTISTA ganha mais de 16 mil habitantes em um ano, segundo IBGE. Portal G1 Santos. Disponível em <http://g1.globo.com/sp/santosregiao/noticia/2014/08/baixada-santista-ganha-mais-de-16-mil-habitantes-em-um-anosegundo-ibge.html>. Acesso em: 29 ago. 2014.

BACKES, M.; BAUMGARTNER, C.; PILS, M.; PLÜSS, C. Red Card for Tourism: Ten Principles and Challenges for a Sustainable Tourism Development in the 21st Century. The NGO Network for Sustainable Tourism Development. Germany: DANTE (Die Arbeitsgemeinschaft für Nachhaltige Tourismus Entwicklung), 2002. Disponível: $<$ http://www.unep.fr/shared/publications/cdrom/WEBx0139xPA/statmnts/pdfs/piause.p df>. Acesso em: 11 mar. 2013. 
BRASIL. Ministério do Meio Ambiente. A Convenção sobre Diversidade Biológica. Série Biodiversidade no. 1. Coordenação Geral Bráulio F. S. Dias MMA/SBF/DCBio. Brasília: Ministério do Meio Ambiente, 2000. Disponível em <http://www.mma.gov.br/estruturas/sbf chm rbbio/ arquivos/cdbport 72.pdf>.

Acesso em: 30 abr. 2013.

BRASIL. Ministério do Turismo. Plano Nacional de Turismo 2013-2016: o Turismo fazendo muito mais pelo Brasil. Brasília: Ministério do Turismo, 2013. Disponível em: <http://www.turismo.gov.br/turismo/o ministerio/plano nacional/>. Acesso em: 22 set. 2013.

BRUNDTLAND, G.H. (Coord.) Nosso Futuro Comum. Rio de Janeiro: Fundação Getúlio Vargas, 1991.

CORRÊA, F.A. Reserva da Biosfera da Mata Atlântica: roteiro para o entendimento de seus objetivos e seu sistema de gestão. São Paulo: Consórcio da Mata Atlântica e Conselho Nacional da Reserva da Biosfera da Mata Atlântica, 1995. 27p.

DOWBOR, L. Governabilidade e Descentralização. Revista do Servidor Público, Brasília, vol. 118, n. 1, p. 95-117, jan./jul. 1994.

FIERZ, M.S.M. As abordagens sistêmicas e do equilíbrio dinâmico na análise da fragilidade ambiental do litoral do estado de São Paulo: contribuição à geomorfologia das planícies costeiras. 2008. 394 p. Tese (Doutorado em Geografia) - Departamento de Geografia, Universidade de São Paulo.

IBGE. Instituto Brasileiro de Geografia e Estatística. Censo Demográfico 2010. Disponível em: <http://www.censo2010.ibge.gov.br>. Acesso em: 03 nov. 2012.

IBGE. Instituto Brasileiro de Geografia e Estatística. Censo Demográfico 2013. Disponível em <http://www.censo2013.ibge.gov.br>. Acesso em: 29 dez. 2014.

INESC. Instituto de Estudos Socioeconômicos. Boletim Orçamento e Política Ambiental. Edição 27, Ano X, Dezembro de 2011. Disponível em: $<$ http://www.inesc.org.br/biblioteca/publicacoes/textos/boletim-orcamento-epolitica-ambiental/>. Acesso em: 17 jul. 2013.

INSTITUTO PÓLIS. Agendas de Desenvolvimento Sustentável: contribuições para a Baixada Santista e Litoral Norte de São Paulo. Projeto Litoral Sustentável: Desenvolvimento com Inclusão Social. Coordenação Geral: Nelson Saule Jr.; Danielle Klintowitz e Guadalupe M. J. Abib de Almeida.São Paulo: Instituto Pólis, 2013. Disponível em <file:///C:/Users/SILVIA/Downloads/Agendas-Municipais-eRegional-de-Desenvolvimento-Sustentavel-Projeto-Litoral-Sustentavel.pdf $>$.

Acesso em 11 ago. 2014.

IPEA. Instituto de Pesquisa Econômica Aplicada. Objetivos de desenvolvimento do milênio: $2^{\circ}$ relatório nacional de acompanhamento 2005. Supervisão: Grupo Técnico para o acompanhamento dos ODM. Brasília: IPEA, 2005. Disponível em: <http://www.pnud.org.br/Docs/2 RelatorioNacionalAcompanhamentoODM.pdf>.

Acesso em: 19 mai. 2014. 
IPEA; ONU; SPM; SEPPIR. Retrato das desigualdades de gênero e raça. $4^{a}$ ed. Organização: IPEA (Instituto de Pesquisa Econômica Aplicada); ONU Mulheres (Organização das Nações Unidas); SPM (Secretaria de Políticas para as Mulheres); e SEPPIR (Secretaria de Políticas de Promoção da Igualdade Racial). Brasília: IPEA, $2011 . \quad 39 \quad$ p. $\quad 39$ Disponível $<$ http://www.ipea.gov.br/portal/index.php?option=com content\&view=article\&id=12 893>. Acesso em 23 dez. 2013.

IPEA. Objetivos de Desenvolvimento do Milênio: $5^{\circ}$ Relatório Nacional de Acompanhamento. Coordenação: Instituto de Pesquisa Econômica Aplicada e Secretaria de Planejamento e Investimentos Estratégicos. Supervisão: Grupo Técnico para o acompanhamento dos ODM. Brasília: IPEA: MP, SPI, 2014. 208 p. Disponível $<$ http://www.pnud.org.br/Docs/5 RelatorioNacionalAcompanhamentoODM.pdf >. Acesso em 11 dez. 2014.

IRVING, M.A. Ecoturismo em áreas protegidas: um desafio no contexto brasileiro. Espaço e Geografia, v.3, oํ 1, págs. 47-61. 2000.

LINO, C.F.; AZEVEDO, C.M.A.; ALBUQUERQUE, J.L.R.; COSTA, J.P.O. (Orgs). Convenção da diversidade biológica: metas de Aichi 2020 e protocolo de Nagoya (acesso e repartição de benefícios do uso de recursos naturais). Cadernos da Reserva da Biosfera da Mata Atlântica. Série 1: Conservação e áreas protegidas, n. 41.São Paulo: Conselho Nacional da Reserva da Biosfera da Mata Atlântica, 2011. 64 p.

ONU. Organização das Nações Unidas. Declaração Final Da Conferência Das Nações Unidas Sobre Desenvolvimento Sustentável (Rio + 20): O Futuro Que Queremos. Conferência das Nações Unidas sobre Desenvolvimento Sustentável, 20 a 22 de Junho de 2012. Revisão: Julia Crochemore Restrepo e Prof. Dr. Daniel José da Silva. Rio de Janeiro: Organização das Nações Unidas no Brasil, 2012. Disponível em: <http://www.mma.gov.br/port/conama/processos/61AA3835/OFuturo-que-queremos1.pdf>. Acesso em 21 ago. 2013.

REGULES, M.P.P.; CAVALCANTI, P.A.B.; TIBÉRIO, W.; SILVA, V.C. Ética, meio ambiente e cidadania para o turismo. São Paulo: IPSIS, 2007.

SÃO PAULO (Estado). Diretrizes para uma Política Estadual de Ecoturismo. São Paulo: Secretaria do Meio Ambiente, 1997.

SÃO PAULO (Estado). Secretaria de Estado de Economia e Planejamento (SEP) e Agência Metropolitana da Baixada Santista (AGEM). Padrões Socioespaciais. São Paulo: AGEM, 2006.

SÃO PAULO (Estado). Fundação Sistema Estadual de Análise de Dados (SEADE). Tendências do Emprego e Características das Ocupações no Estado de São Paulo 2003-2009. São Paulo: SEADE, 2010a.

SÃO PAULO. (Estado). Instituto Florestal. Inventário Florestal da Vegetação Natural do Estado de São Paulo 2008/2009. São Paulo: Instituto Florestal, 2010b.

SÃO PAULO (Estado). Secretaria do Meio Ambiente (SMA) e Coordenadoria de Planejamento Ambiental (CPLA). Meio Ambiente Paulista: Relatório da Qualidade Ambiental 2011. Organização: Fabiano Eduardo Lagazzi Figueiredo. São Paulo: SMA/CPLA, 2011. 
SÃO PAULO (Estado). Secretaria do Meio Ambiente. Zoneamento ecológicoeconômico do setor costeiro da Baixada Santista. Secretaria do Meio Ambiente do Estado de São Paulo (SMA) e Coordenadoria de Planejamento Ambiental (CPLA). Organização Luiz Roberto Numa de Oliveira. São Paulo: SMA, 2013. 104p. Disponível em: <http://www.ambiente.sp.gov.br>. Acesso em 12/07/2014.

TAKAHASHI, L.Y. Uso público em Unidades de Conservação. Cadernos de conservação. Paraná: Fundação $O$ Boticário de Proteção à Natureza, ano 02, out.2004.

TELES, R.M.S.; NOGUEIRA, S.M.B. Novos arranjos espaciais da oferta turística associados às unidades de conservação presentes em espaços metropolitanos: $O$ caso das áreas de expansão urbana da metrópole paulista no entorno do parque estadual do Jaraguá (SP).EI Periplo Sustentable, v. 9, p. 177-192, 2013.

TERRA DE DIREITOS. COP/MOP de Nagoya: de um marco de direitos humanos para a preservação da biodiversidade às propostas de financeirização da natureza. Organização Não Governamental de Direitos Humanos Terra de Direitos e Heinrich Böll Stiftung. Brasília: Terra de Direitos, 2012. Disponível em $<$ http://terradedireitos.org.br/wp-content/uploads/2012/10/Boletim-TDD-

CDB 2012.pdf>. Aceso em: 02 fev. 2014.

UNB; PUCMinas; IDHS e PNUD. Objetivo 7: Garantir a Sustentabilidade Ambiental. Coleção de estudos temáticos sobre os Objetivos do Desenvolvimento do Milênio. Organizadores: UNB (Universidade de Brasília); PUCMinas (Pontifícia Universidade Católica de Minas Gerais); IDHS (Instituto para o Desenvolvimento Humano e Sustentável); PENUD (Programa das Nações Unidas para o Desenvolvimento). Belo Horizonte: PUC Minas/IDHS, 2004. Disponível em: $<$ http://www.mma.gov.br/port/sdi/ea/deds/arqs/objmil sustamb.pdf $>$. Acesso em 16 jun. 2012.

UNCTAD. The United Nations Conference on Trade and Development. Asia-Pacific: e-Tourism for Growth. Matching Market Efficiency and Social Inclusion. Final Report. Organized by: UNCTAD and Government of Malaysia. Sabah, Malaysia: 13 - 14 March 2007. Disponível em: $<$ http://unctad.org/Sections/wcmu/docs/site ecb etourism001.pdf $>$. Acesso em: 24 out. 2012.

UNEP/UNWTO. United Nations Environment Programme (UNEP) and United Nations World Tourism Organization (UNWTO). Making Tourism More Sustainable: a Guide for Policy Makers, UNEP: Paris, 2005. Disponível em: < http://www.unep.org/publications/search/pub details s.asp?ID=3566 >. Acesso em 23 nov. 2014.

UNWTO. World Tourism Organization. Annual Report 2013. Madrid: UNWTO, 2014. Disponível em: <http://media.unwto.org/annual-reports>. Acesso em: 12 ago. 2014.

VEIGA, J.E. Indicadores de sustentabilidade. São Paulo: Estudos Avançados, v. 24, n. 68, 2010. Disponível em: $<$ http://www.scielo.br/scielo.php?script=sci arttext\&pid=S010340142010000100006\&lng=en\&nrm=iso>. Acesso em 28 Dec. 2013.

ZÜNDT, C. Baixada Santista: uso, expansão e ocupação do solo, estruturação de rede urbana regional e metropolização. In: CUNHA, J.M.P. (Org.). Novas Metrópoles Paulistas: População, vulnerabilidade e segregação. 1. ed. Campinas: Núcleo de Estudos de População, 2006, v. 1. 


\section{Nota:}

1 Artigo apresentado originalmente no XV EGAL - Encontro de Geógrafos da América Latina, Havana, Cuba de 06 a 10 de abril de 2015. Publicado em mídia digital nos anais do congresso.

Reinaldo Miranda de Sá Teles: Universidade de São Paulo, São Paulo, SP, Brasil.

E-mail: reiteles@usp.br

Link para o currículo Lattes: http://lattes.cnpq.br/5662794770689990

Silvia Maria Bellato Nogueira: Secretaria do Meio Ambiente do Estado de São Paulo, São Paulo, SP, Brasil.

E-mail: silbellato@gmail.com

Link para o currículo Lattes: http://lattes.cnpq.br/4224787399909676

Data de submissão: 05 de agosto de 2015

Data de recebimento de correções: 17 de fevereiro de 2016

Data do aceite: 17 de fevereiro de 2016

Avaliado anonimamente 